\title{
STUDI HAMBATAN DAN KECEPATAN KAPAL TIPE LAMBUNG SERIES 60 DITINJAU DARI TIGA BENTUK HALUAN KAPAL
}

\author{
Purwo Joko Suranto \\ Fakultas Teknik Program Studi Perkapalan UPN “Veteran” Jakarta \\ email: jekdoank@gmail.com
}

\begin{abstract}
Research that has been done resulting hull of Series 60 is one model of ship hulls. Series 60 hull is used for the a merchant ship to block coefficient range from 0.65 - 080. Research Series 60 hull has great success, the American Towing Tank Conference (ATTC) and the International Towing Tank Conference (ITTC) agreed to fund further research for the Series 60 hull. The results of further research, published by the Society of Naval Architects and Marine enginners (SNAME). hull form series 60 is still widely used for type of commercial ships due to have a midship $U$ is almost square so that traffic carried quite a lot of it is important for commercial ships, in addition to stability is also good. The bow of a ship is part of the greatest pressure and voltages, as the brunt of the water and the ship blows waves. Modeled and analyzed Series 60 Hull with a sloping shape of the bow, the bulbows and $X$-Bow with the main dimension of the vessel : Lpp $=30.97 \mathrm{~m}, B$ $=4.34 \mathrm{~m}, T=1.7 \mathrm{~m}$. To further analyze the effect of the three forms of the bow ship for resistance and speed. Analyzed to three forms of the hull at speeds of 0 to 8.25 knots have resistance almost flat at around 7000 Newton, meaning the ship relatively similar obstacles. At speeds above the 8.25 knots have resistance vessel with a hull tilted began to increase with increasing vessel speed has become increasingly apparent obstacles ships is increasing drastic, especially at a speed of 30 knots have resistance of ship 257733 Newton when compared with resistance vessel for bulbows form who is resistance 230059 Newton or X-bow have resistance 228943 Newton.
\end{abstract}

Keywords : series 60, bulbous bow, $x$-bow, resistance

\section{Pendahuluan}

Pada tahun 1948 - 1960 dilakukan penelitian untuk mendapatkan bentuk lambung kapal . Penelitian tersebut didukung oleh Society of Naval Architects and Marine Enginners (SNAME) dan American Towing Tank Conference (ATTC). Dari Penelitian yang sudah dilakukan, maka dihasilkan lambung kapal Series 60 Kapal Series 60 merupakan salah satu model induk untuk lambung kapal. Lambung Series 60 digunakan untuk lambung kapal niaga yang mempunyai range cb 0,65-08.

Karena penelitian lambung kapal Series 60 meraih kesuksesan yang besar, maka American Towing Tank Conference (ATTC) dan International Towing Tank Conference (ITTC) setuju untuk mendanai penelitian lanjutan mengenai lambung kapal Series 60. Hasil dari penelitian lanjutan tersebut dipublikasikan oleh Society of Naval Architects and Marine Enginners (SNAME).

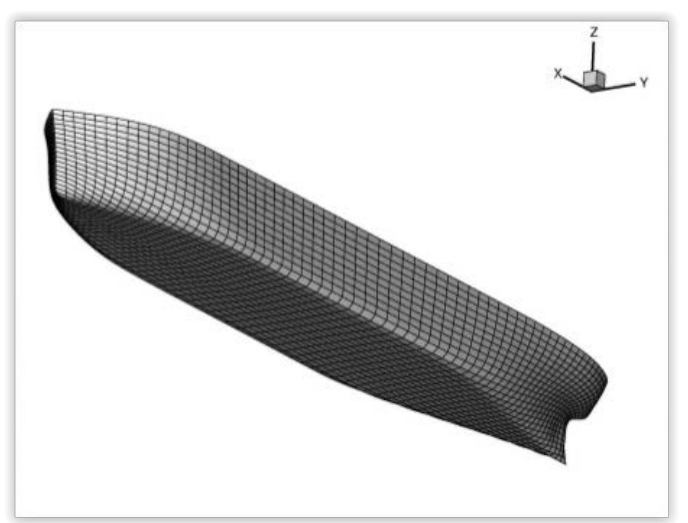

Gambar 1. Lambung Kapal Series 60

Bentuk lambung lambung kapal series 60 ini sampai sekarang masih banyak digunakan untuk jenis kapal-kapal niaga dikarenakan mempunyai bentuk midship $U$ yang hampir berbentuk segi empat sehingga muatan yang diangkut cukup banyak hal ini penting untuk kapal-kapal niaga, selain itu stabilitasnya juga baik.

Haluan sebuah kapal merupakan bagian yang paling besar mendapat tekanan dan tegangantegangan, sebagai akibat terjangan kapal terhadap air dan pukulan-pukulan ombak.

Bentuk Haluan untuk jenis kapal-kapal series 60 kebanyakan berbentuk haluan miring 
sebagaimana terlihat pada gambar 2 dan haluan bentuk Bulbous Bow diperlihatkan pada gambar 3.

Pada era sekarang ini mulai dikembangkan desain haluan kapal bentuk terbaru yaitu haluan kapal berbentuk XBow ditunjukan sebagaimana gambar 4..

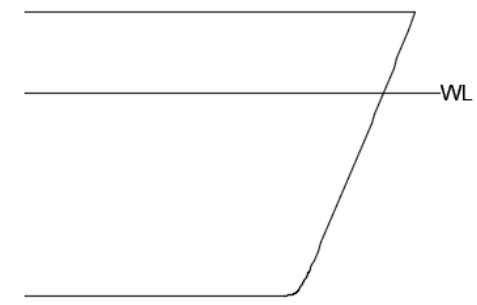

Gambar 2. Bentuk Haluan Miring

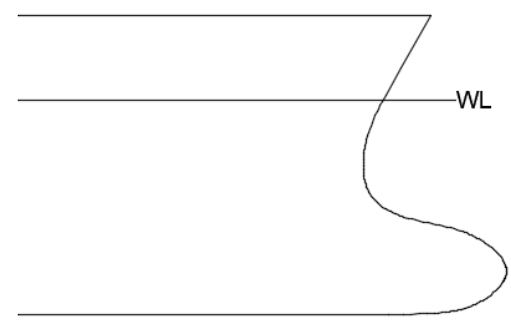

Gambar 3. Bentuk Haluan Bulbows Bow

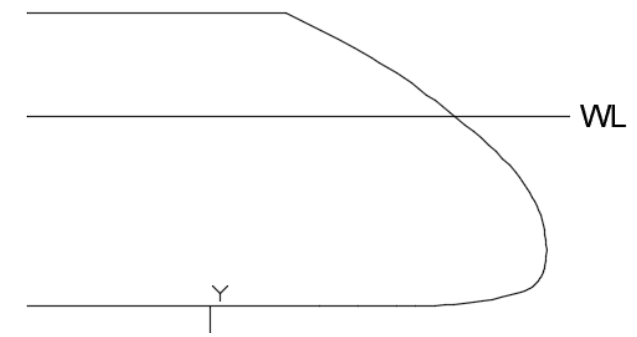

Gambar 4. Bentuk Haluan XBow

Akan dimodelkan Lambung Kapal dengan bentuk haluan miring, bulbows bow dan X-Bow sebagaimana terlihat pada Gambar 2,3 dan 4 dengan menggunakan software maxsurf adapun ketiga ukuran pokok kapal adalah sebagai berikut :

$$
\begin{aligned}
& \mathrm{Lpp}=30.97 \mathrm{~m} . \\
& \mathrm{B}=4.34 \mathrm{~m} . \\
& \mathrm{T}=1.7 \mathrm{~m} .
\end{aligned}
$$

Untuk selanjutnya akan dianalisa pengaruh dari ketiga bentuk haluan kapal tersebut terhahap Hambatan dan Kecepatan kapal dengan menggunakan software Hull Speed.

Karena hambatan badan kapal yang bergerak di air sangat berperan penting terhadap power mesin yang akan digunakan, menurut William
Froude Total Hambatan kapal yang bergerak di fluida adalah sebagai berikut :

$\mathrm{Rt}=\mathrm{Rf}+\mathrm{Rr}$

Dimana :

Rt $=$ Tahanan Gesek

$\mathrm{Rr}=$ Tahanan Sisa

Adapun yang yang dominan dan yang paling bepengaruh serta yang paling besar dari kedua hambatan tersebut adalah hambatan gesek, hambatan ini terjadi karena kapal bergerak di dalam suatu media fluida dalam hal ini air laut sehingga terjadi gesekan antara lambung kapal dengan air laut. Maka menurut William Froude Hambatan Gesek adalah sebagai berikut:

$\mathrm{Rf}=\mathrm{f} \cdot \mathrm{S} \cdot \mathrm{V}^{\mathrm{n}}$

Dimana :

$\mathrm{f}=$ koefisien tahanan gesek

$\mathrm{S}=$ Luas permukaan basah $\left(\mathrm{m}^{2}\right)$

$\mathrm{V}=$ Kecepatan (knots)

\begin{tabular}{|c|c|c|c|c|}
\hline \multirow{2}{*}{$\begin{array}{c}\text { Nature of } \\
\text { Surface }\end{array}$} & \multicolumn{4}{|c|}{ Length, $L$} \\
\hline & 2 feet & 8 feet & 20 feet & $50 \mathrm{feel}$ \\
\hline \multicolumn{5}{|l|}{ Values for $f^{*}$} \\
\hline Varnish & 0.0117 & 0.0121 & 0.0104 & 0.0097 \\
\hline Paraffin & 0.0119 & 0.0100 & 0.0088 & \\
\hline Calico & 0.0281 & 0.0196 & 0.0184 & 0.0170 \\
\hline Fine Sand & 0.0231 & 0.0166 & 0.0137 & 0.0104 \\
\hline Medium Sand & 0.0257 & 0.0178 & 0.0152 & 0.0139 \\
\hline Coarse Sand & 0.0314 & 0.0204 & 0.0168 & $\ldots \ldots$ \\
\hline \multicolumn{5}{|l|}{ Values for $n$} \\
\hline Varnish & 2.00 & 1.85 & 1.85 & 1.83 \\
\hline Paraffin & 1.95 & 1.94 & 1.93 & \\
\hline Calico & 1.93 & 1.92 & 1.89 & 1.87 \\
\hline Fine Sand & 2.00 & 2.00 & 2.00 & 2.06 \\
\hline Medium Sand & 2.00 & 2.00 & 2.00 & 2.00 \\
\hline Coarse Sand & 2.00 & 2.00 & 2.00 & $\ldots$ \\
\hline
\end{tabular}

Adapun daftar table $\mathrm{f}$ dan $\mathrm{n}$ sebagaimana terlihat pada gambar 5 .

Gambar 5. Tabel f dan n menurut Froude

Begitupun juga dengan kecepatan kapal ini akan mempengaruhi besar kecilnya hambatan kapal juga, semakin cepat kapal tersebut maka hambatan kapalnya semakin besar, semakin kecil kecepatannya maka akan semakin kecil juga hambatan kapalnya sebagai mana terlihat pada gambar 6.

Semakin hambatanya besar maka penggunaan Horse Power mesin akan besar pula maka akan mengakibatkan kosumsi BBM yg semakin besar. Demikian pula bila hambatan kapal kecil maka Horse Power yang digunakan akan kecil, sehingga 
dapat memperkecil kosumsi bahan bakar alias lebih irit.

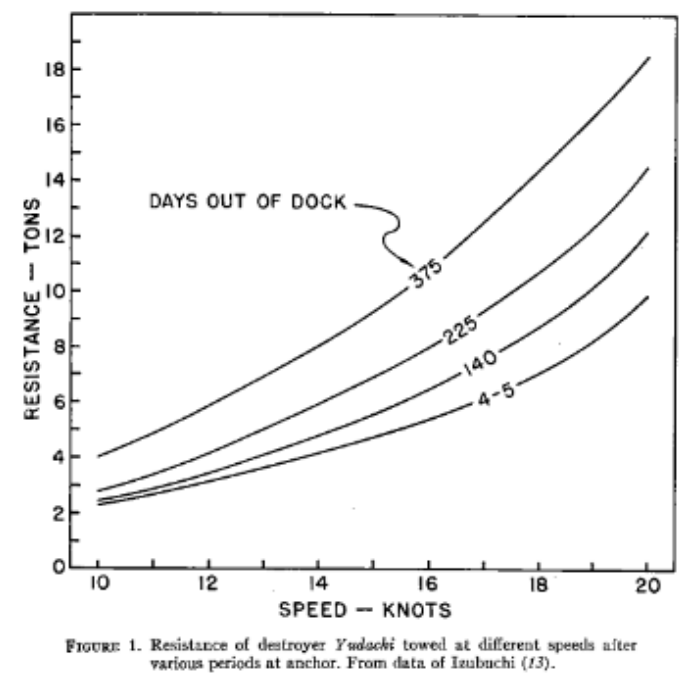

Gambar 6. Grafik Kecepatan dan Hambatan

Pada penelitian ini hambatan kapal akan ditinjau dari segi hambatan totalnya. Menurut Rumus pendekatan dimana untuk sebuah kapal dengan kecepatan 14 knot mempunyai hambatan total yang terdiri dari hambatan gesek sekitar $87 \%$ dan hambatan sisanya sebesar $13 \%$.

\section{Pemodelan}

Tahapan awal dari penelitian ini adalah dengan membuat model kapal menggunakan software maxsurf. Pembuatan model kapal dibuat tiga buah model kapal dengan ukuran pokok yang sama tetapi bentuk dari haluan ketiga kapal tersebut berbeda-beda sebagai berikut :

1. Tipe lambung series 60 dengan, bentuk haluan miring, terlihat pada gambar 7 .

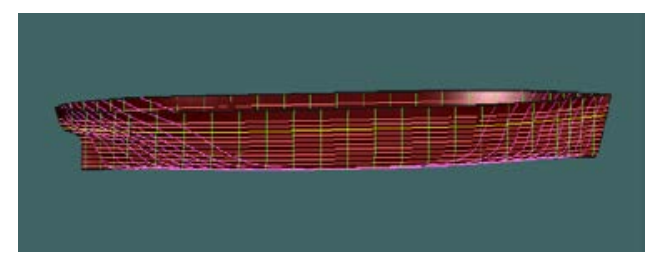

Gambar 7. Lambung Tipe Series 60 dengan bentuk Haluan Miring

2. Tipe lambung series 60 dengan, bentuk haluan Bulbous bow, terlihat pada gambar 8 .

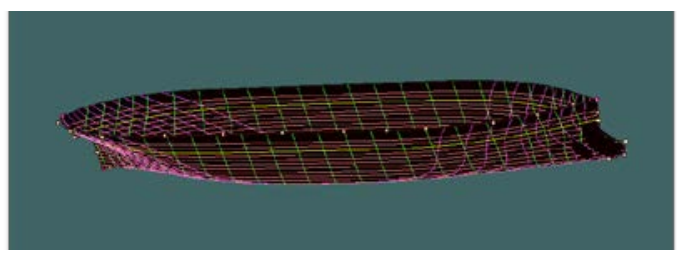

Gambar 8. Lambung Tipe Series 60 dengan bentuk Haluan Bulbows Bow
3. Tipe lambung series 60 dengan, bentuk haluan X-Bow, terlihat pada gambar 9 .

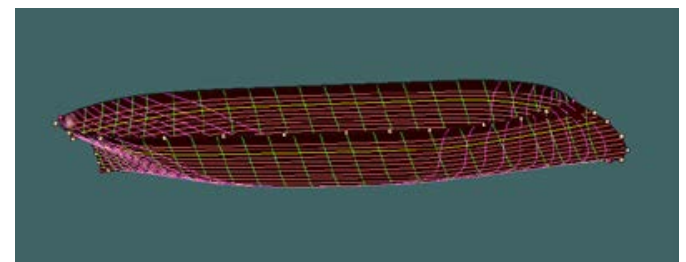

Gambar 9. Lambung Tipe Series 60 dengan bentuk Haluan X-Bow

Dimana ketiga model kapal dengan bentuk haluan yang berbeda, yang sudah dimodelkan di Maxsurf kemudian di lanjutkan dengan menggunakan software Hull Speed agar dapat dianalisa kecepatan dan hambatan dari ketiga bentuk haluan kapal series 60 tersebut.

\section{Analisa di Hull Speed}

Untuk mengetahui hambatan dan kecepatan kapal dari ketiga bentuk lambung series 60 dengan haluan miring, bulbous bow maupun $\mathrm{x}$ bow, digunakan software Hull Speed. Dimana dengan software ini satu persatu dari ketiga model bentuk haluan kapal tersebut dibuka dan kemudian dianalisa dengan menggunakan Metode Holtrop dengan kecepatan 0 sampai 30 knot. Jadi setiap lambung kapal akan dianalisa dengan menggunakan metode dan kecepatan tersebut yang nantinya dapat di bandingkan dan dianalisa hasil dari ketiga lambung kapal tersebut.

Setelah dimasukkan dan diseting di Hull Speed maka didapatlah data grafik dan data tabel. Untuk gambar 10 dan tabel 1 adalah grafik serta data dari lambung tipe series 60 dengan haluan miring, gambar 11 dan tabel 2 adalah grafik serta data dari lambung tipe series 60 dengan haluan bulbous bow sedangkan gambar 12 dan tabel 3 adalah grafik serta data dari lambung tipe series 60 dengan haluan x-bow.

Grafik serta data-data tersebut nantinya akan dianalisa sehingga mendapatkan hasil dan kesimpulan dari ketiga bentuk haluan kapal tersebut.

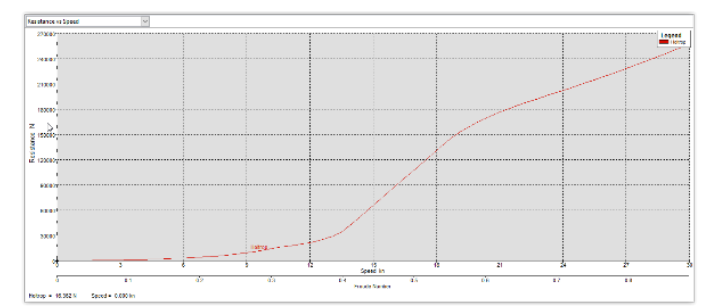

Gambar 10. Grafik Hambatan dan Kecepatan kapal lambung tipe series 60 bentuk haluan miring. 
Tabel 1. Data Hambatan dan Kecepatan kapal lambung tipe series 60 bentuk haluan miring.

\begin{tabular}{|c|c|c|}
\hline Speed (Knot) & Resitance (N) & Power (HP) \\
\hline 0.00 & -- & -- \\
\hline 0.75 & 58.94 & 0.03 \\
\hline 1.50 & 214.07 & 0.22 \\
\hline 2.25 & 456.74 & 0.71 \\
\hline 3.00 & 783.09 & 1.62 \\
\hline 3.75 & 1191.66 & 3.08 \\
\hline 4.50 & 1687.71 & 5.24 \\
\hline 5.25 & 2293.09 & 8.31 \\
\hline 6.00 & 3054.39 & 12.64 \\
\hline 6.75 & 4042.78 & 18.83 \\
\hline 7.50 & 5350.99 & 27.69 \\
\hline 8.25 & 7035.75 & 40.04 \\
\hline 9.00 & 9230.32 & 57.31 \\
\hline 9.75 & 12489.70 & 84.01 \\
\hline 10.50 & 15887.87 & 115.09 \\
\hline 11.25 & 18488.96 & 143.50 \\
\hline 12.00 & 21444.65 & 177.53 \\
\hline 12.75 & 26240.91 & 230.82 \\
\hline 13.50 & 34003.07 & 316.68 \\
\hline 14.25 & 49587.26 & 487.48 \\
\hline 15.00 & 65666.94 & 679.54 \\
\hline 15.75 & 81816.14 & 888.98 \\
\hline 16.50 & 98034.58 & 1115.93 \\
\hline 17.25 & 114321.97 & 1360.48 \\
\hline 18.00 & 130678.04 & 1622.74 \\
\hline 18.75 & 146567.98 & 1895.90 \\
\hline 19.50 & 158285.19 & 2129.36 \\
\hline 20.25 & 168011.25 & 2347.13 \\
\hline 21.00 & 176244.35 & 2553.34 \\
\hline 21.75 & 183456.25 & 2752.75 \\
\hline 22.50 & 190038.01 & 2949.83 \\
\hline 23.25 & 196288.87 & 3148.42 \\
\hline 24.00 & 202425.51 & 3351.59 \\
\hline 24.75 & 208598.11 & 3561.72 \\
\hline 25.50 & 214906.57 & 3780.63 \\
\hline 26.25 & 221414.22 & 4009.68 \\
\hline 27.00 & 228158.52 & 4249.86 \\
\hline 27.75 & 235159.03 & 4501.93 \\
\hline 28.50 & 242423.11 & 4766.43 \\
\hline 29.25 & 249950.00 & 5043.75 \\
\hline 30.00 & 257733.63 & 5334.17 \\
\hline
\end{tabular}

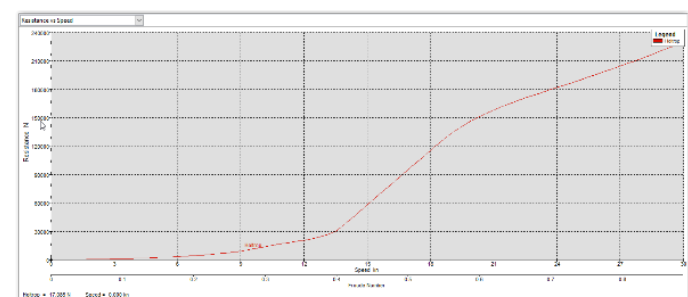

Gambar 11. Grafik Hambatan dan Kecepatan kapal lambung tipe series 60 bentuk haluan bulbows bow.
Tabel 2. Data Hambatan dan Kecepatan kapal lambung tipe series 60 bentuk haluan bulbows bow.

\begin{tabular}{|c|c|c|}
\hline Speed (Knot) & Resitance (N) & Power (HP) \\
\hline 0.00 & -- & -- \\
\hline 0.75 & 61.54 & 0.03 \\
\hline 1.50 & 223.46 & 0.23 \\
\hline 2.25 & 476.73 & 0.74 \\
\hline 3.00 & 817.32 & 1.69 \\
\hline 3.75 & 1243.58 & 3.22 \\
\hline 4.50 & 1760.06 & 5.46 \\
\hline 5.25 & 2385.92 & 8.64 \\
\hline 6.00 & 3161.38 & 13.09 \\
\hline 6.75 & 4147.11 & 19.31 \\
\hline 7.50 & 5417.32 & 28.03 \\
\hline 8.25 & 7044.42 & 40.09 \\
\hline 9.00 & 9018.89 & 56.00 \\
\hline 9.75 & 11965.78 & 80.49 \\
\hline 10.50 & 15416.32 & 111.67 \\
\hline 11.25 & 17997.49 & 139.68 \\
\hline 12.00 & 20381.07 & 168.73 \\
\hline 12.75 & 24026.04 & 211.33 \\
\hline 13.50 & 29996.34 & 279.37 \\
\hline 14.25 & 43631.25 & 428.93 \\
\hline 15.00 & 57782.67 & 597.95 \\
\hline 15.75 & 72006.61 & 782.40 \\
\hline 16.50 & 86302.75 & 982.39 \\
\hline 17.25 & 100670.79 & 1198.03 \\
\hline 18.00 & 115110.47 & 1429.43 \\
\hline 18.75 & 129325.40 & 1672.86 \\
\hline 19.50 & 140706.40 & 1892.88 \\
\hline 20.25 & 150122.94 & 2097.23 \\
\hline 21.00 & 157995.04 & 2288.95 \\
\hline 21.75 & 164762.22 & 2472.24 \\
\hline 22.50 & 170809.41 & 2651.36 \\
\hline 23.25 & 176441.97 & 2830.08 \\
\hline 24.00 & 181887.04 & 3011.53 \\
\hline 24.75 & 187305.70 & 3198.16 \\
\hline 25.50 & 192807.62 & 3391.87 \\
\hline 26.25 & 198464.33 & 3594.07 \\
\hline 27.00 & 204320.00 & 3805.83 \\
\hline 27.75 & 210399.66 & 4027.93 \\
\hline 28.50 & 216715.18 & 4260.97 \\
\hline 29.25 & 223269.56 & 4505.36 \\
\hline 30.00 & 230059.95 & 4761.42 \\
\hline
\end{tabular}

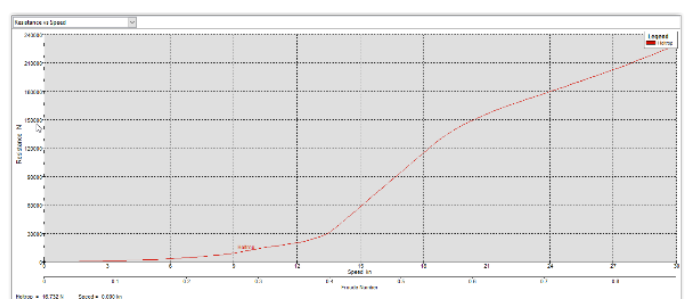

Gambar 12. Grafik Hambatan dan Kecepatan kapal lambung tipe series 60 bentuk haluan x-bow. 
Tabel 3. Data Hambatan dan Kecepatan kapal lambung tipe series 60 bentuk haluan x-bow.

\begin{tabular}{|c|c|c|}
\hline Speed (Knot) & $\begin{array}{c}\text { Resitance } \\
\text { (N) }\end{array}$ & $\begin{array}{c}\text { Power } \\
\text { (HP) }\end{array}$ \\
\hline 0.00 & -- & -- \\
\hline 0.75 & 60.28 & 0.03 \\
\hline 1.50 & 218.89 & 0.23 \\
\hline 2.25 & 467.02 & 0.73 \\
\hline 3.00 & 800.71 & 1.66 \\
\hline 3.75 & 1218.30 & 3.15 \\
\hline 4.50 & 1724.06 & 5.35 \\
\hline 5.25 & 2336.41 & 8.46 \\
\hline 6.00 & 3094.56 & 12.81 \\
\hline 6.75 & 4058.13 & 18.90 \\
\hline 7.50 & 5302.82 & 27.44 \\
\hline 8.25 & 6985.80 & 39.19 \\
\hline 9.00 & 8862.65 & 55.03 \\
\hline 9.75 & 11782.98 & 79.26 \\
\hline 10.50 & 14991.00 & 108.59 \\
\hline 11.25 & 17428.45 & 135.27 \\
\hline 12.00 & 19950.24 & 165.16 \\
\hline 12.75 & 23887.84 & 210.12 \\
\hline 13.50 & 30229.91 & 281.54 \\
\hline 14.25 & 43793.09 & 430.52 \\
\hline 15.00 & 57847.03 & 598.61 \\
\hline 15.75 & 71972.02 & 782.02 \\
\hline 16.50 & 86167.77 & 980.85 \\
\hline 17.25 & 100433.98 & 1195.21 \\
\hline 18.00 & 114770.39 & 1425.20 \\
\hline 18.75 & 128792.26 & 1665.96 \\
\hline 19.50 & 139544.19 & 1877.24 \\
\hline 20.25 & 148482.34 & 2074.31 \\
\hline 21.00 & 156031.72 & 2260.51 \\
\hline 21.75 & 162612.42 & 2439.99 \\
\hline 22.50 & 168581.21 & 2616.77 \\
\hline 23.25 & 174215.54 & 2794.37 \\
\hline 24.00 & 179718.78 & 2975.63 \\
\hline 24.75 & 185233.40 & 3162.78 \\
\hline 25.50 & 190855.22 & 3357.52 \\
\hline 26.25 & 196645.83 & 3561.14 \\
\hline 27.00 & 202642.48 & 3774.58 \\
\hline 27.75 & 208865.44 & 3998.56 \\
\hline 30.00 & 228943.07 & 4738.31 \\
\hline
\end{tabular}

\section{Hasil}

Berdasarkan hasil data dan grafik hambatan dan kecepatan yang sudah disatukan dalam untuk ketiga bentuk haluan kapal yaitu bentuk haluan miring, bulbows bow dan x-bow sebagaimana terlihat pada gambar 13 yang mana grafik warna biru adalah grafik lambung kapal series 60 dengan bentuk lambung miring, grafik warna oranye adalah grafik lambung kapal series 60 dengan bentuk lambung bulbous bow dan grafik warna hijau adalah grafik lambung kapal series 60 dengan bentuk lambung $\mathrm{x}$-bow.

Dari pembacaan grafik dan data tersebut terlihat untuk ketiga bentuk lambung pada kecepatan 0 sampai 8.25 knot mempunyai hambatan kapal yang hampir sama yaitu sekitar 7000 Newton,

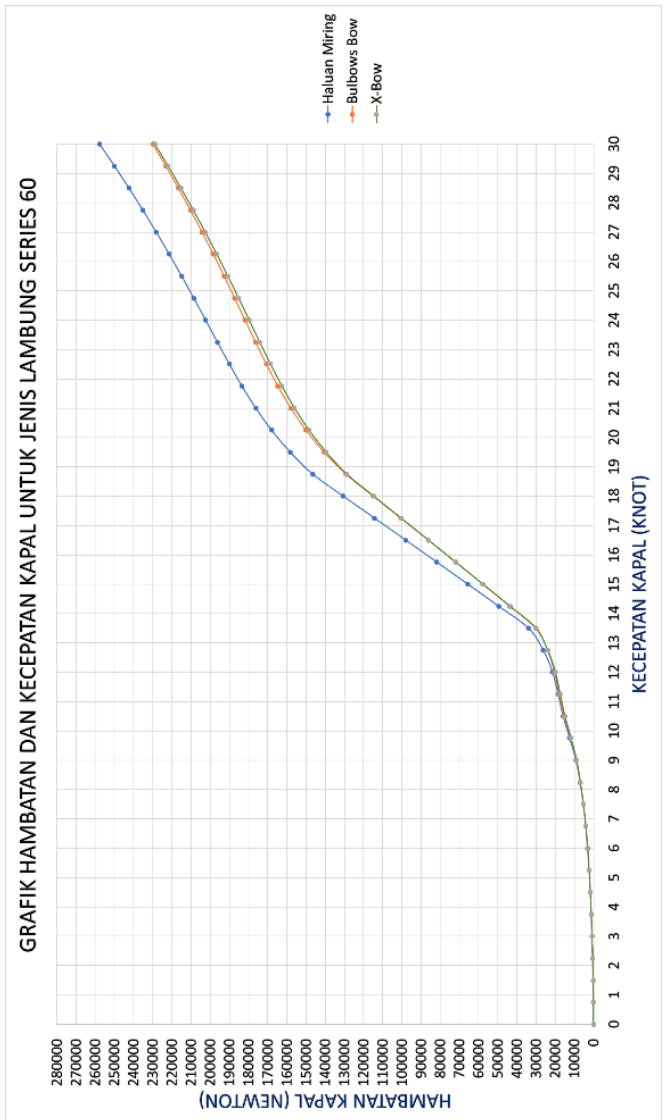

Gambar 13. Grafik Hambatan dan Kecepatan kapal lambung tipe series 60 bentuk ketiga haluan

artinya hambatan kapalnya relative sama. Pada kecepatan diatas 8.25 hambatan kapal dengan lambung miring mulai meningkat seiring dengan bertambahnya kecepatan kapal makan semakin terlihat jelas hambatan kapalnya semakin meningkat drastis terutama pada kecepatan 30 knot terlihat hambatan kapalnya sebesar 257733 Newton bila dibandingkan dengan hambatan kapal untuk bentuk haluan bulbows bow hambatannya 230059 Newton maupun x-bow yang hambatannya 228943 Newton.

Jadi berdasarkan hal tersebut maka seiring bertambahnya kecepatan kapal dari 0 sampai 30 knot, untuk kapal series 60 dengan bentuk lambung bulbous bow dan bentuk x-bow adalah lebih kecil hambatannya, dan dibandingkan lagi antara bulbous bows dan x-bow maka yang paling kecil hambatannya adalah yang bentuk haluan $\mathrm{x}$ bow. 


\section{Simpulan}

Dari ketiga lambung kapal series 60 dengan bentuk haluan yang berbeda beda yaitu bentuk lambung miring, bulbows bow serta x-bow dan ukuran pokok ketiganya adalah sama, setelah dianalisa ternyata ketiga bentuk haluan tersebut mempunyai hambatan yang berbeda-beda. Semakin besar kecepatan kapal antara 0 sampai 30 knot maka semakin jelas terlihat perbedaannya. Kapal dengan bentuk haluan miring pada kecepatan 30 knot mempunyai hambatan yang paling besar yaitu 257733 Newton jika dibandingkan dengan bentuk haluan bulbous bow dan x-bow sedangkan bentuk haluan yang hambatannya paling kecil adalah bentuk haluan $\mathrm{x}$ bow yaitu pada kecepatan kapal 30 knot mempunyai hambatan sebesar 228943 Newton.

\section{Daftar Pustaka}

Maxsurf Modeler. (Version 20). User Manual. 2015 Bentley Systems, Incorporated.

Maxsurf Resistance. (Version 20). User Manual. 2015 Bentley Systems, Incorporated.

Endro, W.D. (2014),

High Speed Ship Total ResistanceCalculation (An Empirical Study), JurnalKapal V11, No 1, dkk (2003), National Maritime Research Institute, On Aerodynamic Characteristics of a

Dyer, Charles. 2002. Fixed Point Iteration. University of Leeds.

Froude, W , Froude R.E. , 1888, The Resistance of Ships

Molland, A.F, Turnock, S.R, Hudson,D.A, Ship Resistance and Propulsion Practical Estimation of Propulsive Power

Larsson,L.L, Raven, H.C., 2010, Ship Resistence and Flow, Society of Naval Architects and Marine Engineers

Douglas, J.F, Gasiorek, J.M, and Swaffield, J.A., 2001, Fluid Mechanics 